\title{
Papers
}

\section{Informing participants of allocation to placebo at trial closure: postal survey}

\author{
Zelda Di Blasi, Ted J Kaptchuk, John Weinman, Jos Kleijnen
}

\begin{abstract}
Objectives To assess whether and how investigators of placebo controlled randomised trials inform participants of their treatment allocation at trial closure and to assess barriers to feedback.

Design Postal survey with a semistructured questionnaire.

Participants All investigators who published a placebo controlled randomised trial in 2000 in five leading medical journals, and a random sample of 120 trials listed in the national research register database.

Main outcome measures Number of investigators who informed participants of their treatment allocation at trial closure, methods for delivering the information, and barriers to unmasking treatment.

Results $45 \%$ of investigators informed either all or most participants of their treatment allocation, and $55 \%$ did not inform any participant or only informed those who asked. The main reasons for not informing participants were that the investigators never considered this option (40\%) or to avoid biasing results at study follow up (24\%).

Conclusion Further research is required to examine sensitive ways to communicate treatment information to trial participants.
\end{abstract}

\section{Introduction}

In 1948 the Medical Research Council introduced a new experimental design to deal with therapeutic uncertainties. ${ }^{1}$ The randomised controlled trial aimed to ensure the absence of systematic differences between treatment and control groups. ${ }^{2}$ Placebossurrogates for a control group receiving no treatment-were gradually adopted to act as dummy therapies to mimic the experimental treatment in appearance but not in substance or chemical structure. ${ }^{3}$ Placebos helped patient retention and allowed the consequences of attention, expectation, suggestion, and natural course to be separated from the effects of the experimental treatment.

Initially investigators could recruit patients into studies without needing to inform or ask them for their consent to participate. Patients would often not be aware that they might be taking placebos. Although this approach may have kept the study purer, since at least the early 1970s it has not been considered ethical to withhold this information from patients before they enter a trial. ${ }^{4}$

In March 2001 the Department of Health issued a research governance framework to ensure that the public could have confidence in, and benefit from, quality research. ${ }^{5}$ The report states that once research findings are established, principal investigators are responsible for feeding back findings to participants or their representatives promptly and appropriately. Study results must be presented in a clear and comprehensible language for the general public and be easily and freely accessible for users and care professionals.

Unmasking treatment allocation is not explicitly discussed in the report. This is particularly relevant for placebo controlled trials and especially for participants who have responded to placebo, for whom treatment disclosure may be a particularly sensitive issue. Placebo responders are likely to have high expectations towards the treatment and to attribute positive health changes to this. ${ }^{6}{ }^{7}$ When participants are informed that their treatment consisted of a sham therapy, reactions may be negative and the placebo response may be disrupted.

We examined the extent to which recently conducted trials conform to some of the recommendations of the research governance framework and whether investigators of placebo controlled clinical trials inform participants of their treatment arm. For those who did inform participants, we assessed ways by which this information was delivered to the placebo group. We assessed barriers to information disclosure and intention to inform participants in the future for investigators who failed to inform trial participants. In addition, we identified whether investigators informed patients of study results.

\section{Methods}

We searched Medline to identify all placebo controlled randomised clinical trials published in 2000 in five leading medical journals: BMJ, Lancet, New England Journal of Medicine, JAMA, and Annals of Internal Medicine. Our search strategy was based on the fourth report developed by the NHS Centre for Reviews and Dissemination (see box). ${ }^{8}$

We also searched the national research register, a register of ongoing and recently completed research projects funded by, or of interest to, the UK's NHS. ${ }^{9} \mathrm{We}$ were able to select a random sample of commercially
Department of
Health Sciences,
University of York,
York YO10 5DD
Zelda Di Blasi
PhD student
Osher Institute,
Harvard Medical
School, 401 Park
Drive, Boston,
MA 02215, USA
Ted Kaptchuk
assistant professor
Unit of Psychology,
Guy's, King's, and
St Thomas's School
of Medicine,
London SE1 9RT
John Weinman
professor
NHS Centre for
Reviews and
Dissemination,
University of York,
York YO10 5DD
Jos Kleijnen
director
Correspondence to:
Z Di Blasi
zdb1@york.ac.uk
bmj.com 2002;325:1329 


\section{Medline search strategy}

1. randomized controlled trial.pt.

2. randomized controlled trials.sh.

3. random allocation.sh.

4. double blind method.sh

5. 1 or 2 or 3 or 4

To include only human studies

6. animal.sh.

7. human.sh.

8.6 not $(6$ and 7$)$

$9.5 \operatorname{not} 8$

10. clinical trial.pt.

11. exp clinical trials/

12. (clin $\$$ adj3 trial\$).ti,ab

13. ((doubl $\$$ or treb\$ or tripl\$) adj3 (blind $\$$ or mask\$)).ti,ab.

14. random.ti,ab.

15. research design.sh.

16.10 or 11 or 12 or 13 or 14 or 15

17. 16 not 8

18. comparative study.sh

19. exp evaluation studies/

20. follow up studies.sh.

21. prospective studies.sh.

22. (control\$ or prospectiv\$ or volunteer\$).ti,ab.

23.18 or 19 or 20 or 21 or 22

24. $23 \operatorname{not} 8$

To include only placebo controlled trials

25. placebos.sh

26. placebo\$.ti,ab.

27. 25 or 26

$28.27 \operatorname{not} 8$

To include only top medical journals

29. bmj.jn

30. lancet.jn

31. new england journal of medicine.jn.

32. jama.jn

33. annals of internal medicine.jn

34.28 and (9 or 17 or 24$)$

35.34 and 35

36. limit 36 to $\mathrm{yr}=2000$

funded and non-commercially funded trials by using a randomisation service based at the Health Services Research Trials Support Unit at York university.

We sent the investigators a letter outlining our aims, along with a short semistructured questionnaire. To increase the response rate we sent out letters to coauthors, and we sent reminders by email and then by post.

\section{Results}

Overall, we excluded 27 of 119 potential trials because they consisted of reviews, articles, letters, editorials, or comments, leaving 92 placebo controlled randomised trials. Of these, 25 were published in the Lancet, 24 in the New England Journal of Medicine, 25 in JAMA, 5 in the BMJ, and 13 in the Annals of Internal Medicine. By using the term "placebo" in the national research register, we identified 1973 completed trials (25 from the Medical Research Council's clinical trials' directory). We selected a random sample of 60 commercial and 60 non-commercial trials.

The response rate to the postal survey was $71 \%$ for investigators of trials published in a medical journal (65 of 92) and 62\% for investigators of trials listed in the national research register (74 of 120): total response rate $66 \%$ (139 of 212). Overall, 23\% (32 of 139 ) of these investigators (mostly of trials published in the register) were unable to complete the questionnaire. In eight cases the trial was never conducted or completed because of inadequate recruitment or lack of funding. Five investigators had moved or retired. In six cases the trial was not placebo controlled or the questionnaire was not filled out because the study was still ongoing. Two investigators believed that ethics approval was needed for them to respond to our questionnaire. In seven cases the trial was either not blind, was open, the investigator never participated in the study, or patients were not entered in the trial. Four investigators responded by forwarding our request to relevant researchers, who never replied.

Overall, 107 investigators completed the questionnaire. Of these, $45 \%$ informed either all or most participants of their treatment allocation, and $55 \%$ did not inform any of their participants or informed only those who asked (table 1).

Investigators of trials selected from the national research register or commercially funded trials were less likely to inform participants than investigators of trials published in a leading journal or investigators of trials not funded commercially.

\section{Informing participants of treatment arm}

Participants were generally informed in person (23 of $48,48 \%$ ), by post ( 12 of $48,25 \%$ ), or by telephone ( 4 of $48,8 \%)$. In five cases more than one method was used and in four cases investigators did not indicate how they informed patients. Information about treatment arm (in person or by telephone, $\mathrm{n}=32$ ) was usually provided by a nurse $(8,25 \%)$, investigator $(7,22 \%)$, doctor $(5,16 \%)$, or more than one professional $(12,38 \%)$. The most common method for informing those randomised to placebo was to simply tell them they were in the placebo arm (54\%) or to give them a common definition of placebo effects $(21 \%)$ (table 2$)$.

A few investigators advised patients to follow up this result with their doctor or gave them the opportunity to ask questions or to discuss the option of the active treatment. In one instance the investigator did not know because "the actual message was given at

Table 1 Unmasking of treatment allocation at study closure in placebo randomised controlled trials by source of publication and funding

\begin{tabular}{|c|c|c|c|c|c|c|c|}
\hline \multirow[b]{2}{*}{ Extent of informing participants } & \multirow[b]{2}{*}{ No of trials } & \multicolumn{2}{|c|}{ Source of publication } & \multicolumn{4}{|c|}{ Funding } \\
\hline & & Journal & Register* & Commercial & Non-commercial & $\begin{array}{l}\text { Commercial and } \\
\text { non-commercial }\end{array}$ & $\begin{array}{l}\text { Information not } \\
\text { available }\end{array}$ \\
\hline Informed all participants of treatment arm & 40 & 26 & 14 & 13 & 20 & 5 & 2 \\
\hline Did not inform any participants of treatment arm & 53 & 27 & 26 & 25 & 15 & 8 & 5 \\
\hline Informed only participants who asked & 6 & 3 & 3 & 6 & 0 & 0 & 0 \\
\hline
\end{tabular}

${ }^{\star}$ National research register. 
the discretion of the physician." Some of the studies used a crossover design and patients were simply told they received both a placebo and an active treatment. In one of these studies, patients were also told that if they responded to placebo this probably resulted from being in a trial and the positive effects of placebo. In three cases, investigators explained the effect as a result of spontaneous remission.

\section{Reasons for not informing participants of treatment arm}

Overall, 53 investigators never informed any of their trial participants about treatment allocation. The most common reasons were that they never considered this option (21 investigators) or that they wanted to avoid biasing results at study follow up (12 investigators), often referring to studies that were still ongoing. Eight investigators wanted to avoid extra costs and six wanted to avoid both extra costs and administrative work. Six investigators believed that participants did not need to know; two explained that this was because of the crossover nature of the study. In three cases participants had died, and in single instances participants were not informed to avoid interfering with the doctor-patient relationship, because it was not relevant as it was "rather old news," to avoid distressing or upsetting patients, and because it was not part of the methodology. Difficulty in contacting patients was highlighted in two studies. In one case patients came from an isolated community in Kenya and it would have been difficult to trace them after discharge. In another case the sample was based in Sri Lanka, and participants lived more than 125 miles $(200 \mathrm{~km})$ from the research facility. Many of the patients were poor and did not have a postal address. Follow up was considered pointless as previous attempts had a less than $20 \%$ success rate.

Of the 53 investigators who did not inform participants, $40(75 \%)$ would consider informing participants of their treatment allocation in future studies.

\section{Informing participants of study findings}

Many (32 of 48; 67\%) of the investigators who did inform participants, also informed or would inform all or most participants of the study results (table 3). In trials where participants were not informed of their treatment arm, five (9\%) investigators informed participants of study results.

Although investigators were not directly asked about reasons for not informing participants of study findings, several did give an explanation. Reasons included that the study was ongoing and results were being analysed, the results were "too distant in time" and "rather old news," it was difficult to trace patients, the results were unclear, none of the patients asked, they were never asked by their sponsors, and most of the uninformed participants were dead.

\section{Discussion}

Participants have less than a $50 \%$ chance of being informed of their treatment allocation to placebo at the end of a trial. The main reason for not unmasking treatment allocation was that investigators never considered this option or that they wanted to avoid biasing results at follow up. A wide range of methods were used to inform participants.
Table 2 Method for informing participants about treatment allocation at study closure

\begin{tabular}{lc} 
Method for informing participants & $\begin{array}{c}\text { No (\%) of } \\
\text { participants } \\
\text { (n=48) }\end{array}$ \\
\hline Told they were in placebo arm & $26(54)$ \\
\hline Told they were in placebo arm and given common definition of placebo effects & $10(21)$ \\
\hline Told they received active treatment and placebo in crossover study & $4(8)$ \\
\hline Told placebo response derived from positive effects of being in trial & $4(8)$ \\
\hline Told placebo response derived from positive effects of placebos & $2(4)$ \\
\hline Told placebo response derived from positive effects of both being in trial and placebos & $3(6)$ \\
\hline Told placebo response derived from natural or spontaneous remission & $3(6)$ \\
\hline Data on how patients were informed not given & $8(17)$ \\
\hline
\end{tabular}

Patients need to be treated as participants rather than subjects by increasing their involvement in the trial process. Consumer involvement has been shown to help priorities and to refine trial questions, improving the quality of patient information and making the study more relevant to patients' needs..$^{11} 11$

During the informed consent procedure patients are told that they may receive a placebo; this is usually described as a harmless inactive substance or an inactive dummy drug. We found that the most common method of informing patients in the placebo arm was to simply tell them that they were in this arm, without giving possible explanations for this effect. Just as knowing that patients have a $50 \%$ chance of being randomised to a placebo has been shown to influence health outcomes, it is possible that the placebo response may be disrupted when the treatment is unmasked to patients who have responded. ${ }^{12}$ Unmasking the allocation of placebo may be a source of confusion and disappointment to patients and may even damage clinical relationships and have negative effects on patients' health, particularly in placebo surgery. For this reason, feedback should be handled sensitively. A recent trial evaluating the effects of antidepressants found that when placebo responders were told that they were receiving a placebo their mood deteriorated. ${ }^{13}$ Within a month $70 \%$ of the patients needed antidepressants. ${ }^{14}$

In another study, 50 patients with depression who responded to placebos over a 10 day single blind trial were randomised in a double blind way to either continue taking placebos for six weeks or to stop treatment. Half in each group relapsed at six weeks. ${ }^{15}$ Therefore unmasking had no effect.

To avoid negative thoughts, misconceptions, or mistrust in health professionals, patients must be well informed. They could be told about the various debates on the therapeutic effectiveness of placebos, but that there is growing evidence for the healing effects of psychological and social factors, such as positive expectations and good patient-doctor relationships. ${ }^{16} 17$

\section{Study limitations}

The lower response rate from investigators of trials listed in the national research register is partly due to

Table 3 Extent of informing participants of results at study closure. Values are numbers (percentages) of participants

\begin{tabular}{lccc} 
Extent of informing participants & $\begin{array}{c}\text { Informed } \\
\mathbf{( n = 4 8 )}\end{array}$ & $\begin{array}{c}\text { Not informed } \\
\mathbf{( n = 5 3 )}\end{array}$ & $\begin{array}{c}\text { Informed only after } \\
\text { inquiry (n=6) }\end{array}$ \\
\hline All or most informed & $32(67)$ & $5(9)$ & - \\
\hline Only those who asked informed & $6(13)$ & $7(13)$ & $4(67)$ \\
\hline Nobody informed & $6(15)$ & $37(70)$ & $2(33)$ \\
\hline Information not available & $4(8)$ & $4(8)$ & - \\
\hline
\end{tabular}




\section{What is already known on this topic}

Information is poor on the nature, extent, and effect of informing participants of placebo controlled randomised trials about their treatment allocation at trial closure

Less than $50 \%$ of participants receiving placebo are informed about their treatment allocation

\section{What this study adds}

No standard procedure is available for informing patients of their treatment arm or of study results at the end of a trial

Effective and sensitive ways of communicating treatment allocation to participants are required, as is information on the effects on placebo responders

our inability to contact coauthors, as the name of only one investigator is provided. At times up to six trials were registered under the same investigator, who failed to respond to repeated requests. Many of the trials in the register were never completed, due to a lack of funding or low recruitment rates, so although the investigators replied they were unable to complete our questionnaire.

\section{Practical and research implications}

A major gap is apparent in the literature examining patient understanding of placebos and their effect. Although there has been extensive discussion on the ethics of giving placebos, we are unaware of any systematic discussions on informing patients and full disclosure at trial completion. ${ }^{18}$ If feeding back treatment allocation and study results to the participants of placebo controlled trials is to become a standard part of trial protocols, research is required to examine effective and sensitive ways to communicate such information to participants who want to be informed. Issues that need to be evaluated are at what stage participants should be informed, whose role it is to inform patients, and how best to feed back information in large multicentre trials. Views about treatment should be explored, assessing, for example, the basis of preferences and examining when unmasking may not be appropriate, such as in studies with long term follow up.

We thank the responders to our questionnaire, Kath Wright for help in searching the databases, Simon Coulton for help in the randomisation service, Howard Leventhal and David Reilly for discussions on the psychology of placebo unmasking, and Colin Bradley and Musetta Joyce for their comments on the final drafts. ZDB is funded by a PhD studentship from the Medical Research Council.

Contributors: ZDB and TK conceived and planned the study. ZDB collected, analysed, and interpreted the data and wrote the paper. TK provided constructive criticism on the study design, analysis, and interpretation of the findings, and contributed to all written documents. JW commented on the study design and process and on all draft manuscripts. JK coordinated and supported the study design, data analysis, and interpretation, and commented on all revisions; he will act as guarantor for the paper.

Funding: None.

Competing interests: None declared.

1 Chalmers I. Comparing like with like: some historical milestones in the evolution of methods to create unbiased comparison groups in therapeutic experiments. Int J Epidemiol 2001;30:1156-64.

2 Armitage P. The role of randomization in clinical trials. Stat Med 1982;1:345-52.

3 Kaptchuk TJ. Intentional ignorance: a history of blind assessment and placebo controls in medicine. Bull Hist Med 1998;72:389-433.

4 Faden RR, Beauchamp TL. A history and theory of informed consent. Oxford: Oxford University Press, 1986.

5 Department of Health. Research governance framework for health and social care. London: Department of Health, 2001.

6 Crow R, Gage H, Hampson H, Hart J, Kimber A, Thomas H. The role of expectancies in the placebo effect and in the delivery of health care: a systematic review. Health Technol Assess 1999;3(3):1-98.

7 Lundh LG. Placebo beliefs and health. A cognitive-emotional model. Scand J Psychol 1987;28:128-43.

8 NHS Centre for Reviews and Dissemination. Undertaking systematic reviews of research on effectiveness: CRD guidelines for those carrying out or commissioning reviews. York: NHS Centre for Reviews and Dissemination, University of York, 2001. (Report No 4.)

9 National research register, issue 3, 2001. www.doh.gov.uk/nrr.htm (accessed 5 Apr 2002).

10 Hanley B, Truesdale A, King A, Elbourne D, Chalmers I. Involving consumers in designing, conducting, and interpreting randomised controlled trials: questionnaire survey. BMJ 2001;322:519-23.

11 Royle J, Oliver S. Consumers are helping to prioritise research. BMJ 2001;323:48-9.

12 Bergmann JF, Chassany O, Gandiol J, Deblois P, Kanis JA, Segrestaa J, et al. A randomised clinical trial of the effect of informed consent on the analgesic activity of placebo and naproxen in cancer pain. Clin Trials Meta-Analysis 1994;29:41-7.

13 Leuchter AF, Cook IA, Witte EA, Morgan M, Abrams M. Changes in brain function of depressed subjects during treatment with placebo. Am J Psychiatry 2002;159:122-9.

14 Fox M. Brain scan study shows how placebo aids depression. Reuters, 2002. www.forbes.com/newswire/2002/01/01/rtr467478.html (accessed 8 Feb 2002).

15 Rabkin JG, McGrath PJ, Quitkin FM, Tricamo E, Stewart JW, Klein DF. Effects of pill-giving on maintenance of placebo response in patients with chronic mild depression. Am J Psychiatry 1990:147:1622-6.

16 Hrobjartsson A, Gotzsche PC. Is the placebo powerless? An analysis of clinical trials comparing placebo with no treatment. $N$ Engl J Med 2001;344:1594-602.

17 Di Blasi Z, Harkness E, Ernst E, Georgiou A, Kleijnen J. Influence of context effects on health outcomes: a systematic review. Lancet 2001;357: $757-62$.

18 Temple R, Ellenberg SS. Placebo-controlled trials and active-control trials in the evaluation of new treatments. Part 1: ethical and scientific issues. Ann Intern Med 2000;133:455-63.

(Accepted 5 September 2002) 